\title{
AS CORES DO AMBIENTE DA UNIDADE DE TERAPIA INTENSIVA
}

\section{THE COLORS IN ENVIRONMENT OF THE UNIT OF INTENSIVE THERAPY}

\section{LOS COLORES EN EL AMBIENTE DE LA UNIDAD DE LA TERAPIA INTENSIVA}

\author{
Nélio Barbosa Boccanera ${ }^{1}$ \\ Sulvia Fernandes Borges Boccanera ${ }^{2}$ \\ Maria Alves Barbosa ${ }^{3}$ \\ Virginia Visconde Brasil ${ }^{3}$ \\ Marcelo Medeiros ${ }^{4}$
}

RESUMO: Os objetivos deste trabalho foram descrever as cores mais freqüentemente utilizadas nas paredes, tetos, mobiliários e roupas das Unidades de Terapia Intensiva e verificar com os funcionários e pacientes desta unidade as cores que gostariam que existissem dentro deste ambiente e a associação que eles estabelecem com as cores. Foi realizada pesquisa descritiva exploratória, com enfoque quanti-qualitativo. A amostra foi constituída de pacientes e profissionais da UTI de três hospitais públicos de Goiânia em 2002. Observou-se a existência de cores monótonas e neutras nestes ambientes, em tons que vão do branco ao preto, enquanto outras nuanças de cores aparecem num percentual menor. Constatou-se uma preferência pelas cores azul-claro, branco, verde-claro e amarelo entre os dois seguimentos pesquisados. Concluiu-se que as pessoas estabelecem associações com as cores; que a cor pode auxiliar no estabelecimento do equilíbrio e contribuir para harmonia do corpo, da mente e das emoções.

PALAVRAS CHAVES: Ambiente de Instituições de Saúde; Cuidados Intensivos; Terapia pela Cor.

ABSTRACT: The objective of this work was to describe the colors more frequently used in Intensive Care units and to verify with the employees and patient of this the colors that would like that existed inside of this. The exploratory and descriptive research was used, with quanti-qualitative focus. The sample was constituted of patients and professionals of Intensive Care units of three public hospitals of Goiânia in 2002. It was observed in this study, that we have monotonous and neutral colors in these adapt, in tones that are going from the white to the black, the other nuances of colors appear in a percentile one very smaller. A preference was verified by the colors blueclearing, white, green-clear and yellow among the two researched continuations. We conclude that people establish associations with colors; and it can help for balance establishment and to contribute for body, mind and emotions harmony.

KEYWORDS: Health Facility Enviroment; Intensive Care; Color Therapy.

\footnotetext{
${ }^{1}$ Enfermeiro. Intensivista do Hospital de Clínicas da Universidade Federal de Goiás e do Hospital de Doenças Tropicais do Estado de Goiás. Especialista em Epidemiologia; Terapia Intensiva; e Arte Terapia. Contatos:. Residente na rua 227, $n^{\circ} 515$, aptº101, residencial Veneza, Setor Universitário, Goiânia - Goiás, CEP - 74605-080, e-mail nbarbosa@hc.ufg.br

2 Enfermeira. Psicóloga. Gerente de Enfermagem do Pronto Socorro do Hospital de Clínicas da Universidade Federal de Goiás. Intensivista do Hospital Geral de Goiânia. Licenciada em Enfermagem. Especialista em Pediatria; e Terapia Intensiva. e-mail nbarbosa@hc.ufg.br

3 Enfermeira. Doutora em Enfermagem. Professora. da Faculdade de Enfermagem da Universidade Federal de Goiás.

${ }^{4}$ Enfermeiro. Doutor em Enfermagem. Professor da Faculdade de Enfermagem da Universidade Federal de Goiás.
} 
RESUMEN: Los objetivos de este trabajo fueran describir los colores más frecuentemente usados en las paredes, techos, muebles y ropas de las Unidades de Cuidado Intensivo y verificar con los enfermeros y paciente de esto unidades los colores que quisieran existir en la unidad que están. La investigación fuera del tipo descriptiva y exploratoria, con abordaje quanti-cualitativo. La muestra fue constituida de pacientes y de profesionales de las unidades de cuidado intensivo de tres hospitales públicos de Goiânia en 2002. Fue observado en este estudio la existencia de colores monótonas y neutrales en éstos ambientes, en los tonos que van del blanco al negro, enguanto los otros matices de colores aparecen en un porcentaje uno muy más pequeño. Una preferencia fue verificada por el azul-claro de los colores, blanco, verde-claro y amarillo entre las dos continuaciones investigadas. Concluimos que las personas establecen asociaciones con colores, que esto puede ayudar para el establecimiento del equilibrio e contribuir para la armonía del cuerpo, de la mente e de las emociones

PALABRAS CLAVES: Ambiente de Instituciones de Salud; Cuidados Intensivos; Terapia por Color.

\section{INTRODUÇÃO:}

O tema em estudo aborda as cores no ambiente da Unidade de Terapia Intensiva (UTI). TOBIAS (1986) recomenda a atenuação do ambiente através de cores e desenhos pintados na parede, como forma de diminuir as tensões emocionais provocados pelo desconhecido.

Artifícios simples tais como a utilização de cor adequada no ambiente, podem amenizar o estresse das pessoas internadas ou que trabalham na UTI. A identificação das cores presentes dentro das UTI permite conhecer se elas estão sendo utilizadas adequadamente e contribuir desta forma para a amenização do estresse naquele ambiente.

A harmonia das cores nos mobiliários, roupas, paredes, piso, teto e na decoração é relevante, se considerarmos o período de internação do paciente e de trabalho dos profissionais.

O contato apenas com cores monótonas ou que lembram doenças, morte, podem interferir na avaliação física e nos aspectos emocionais e psicológicos de forma consciente ou inconsciente.

A realização do presente trabalho justifica-se porque, entre outros aspectos, os pacientes que permanecem na UTI sofrem de várias privações sensoriais, dentre elas a satisfação visual. Do mesmo modo, as pessoas que ali trabalham também estão expostas por muitas horas a um ambiente que precisa, no mínimo, ser agradável e confortante.

Apesar de ser reconhecida a importância das cores na vida das pessoas, na literatura foram encontrados poucos trabalhos referentes à utilização de cores no ambiente hospitalar.

O desenvolvimento do trabalho poderá trazer contribuições importantes à prática hospitalar, principalmente aquelas situações relacionadas ao conforto, ao estado de ânimo e relacionamentos na Unidade de Terapia Intensiva.

\section{OBJETIVOS:}

Descrever as cores mais freqüentemente utilizadas nas paredes, tetos, mobiliários e roupas das Unidades de Terapia Intensiva e verificar com os funcionários e pacientes destas unidades as cores que gostariam que existissem dentro deste ambiente e a associação que eles estabelecem com as cores.

\section{METODOLOGIA}

Trata-se de um estudo descritivo exploratório com abordagem quanti-qualitativo realizado em 2002 nas unidades de terapia intensiva de adultos de três hospitais públicos com a participação de funcionários e pacientes que estiveram presentes no período da coleta de dados e que se dispuseram a participar da pesquisa.

Como instrumento de coleta utilizou-se a entrevista individual semi-estruturada, aplicada entre profissionais e pacientes das UTI em horários disponíveis. Foram também realizadas observações dirigidas, com a finalidade de identificar as cores predominantes nas paredes, no teto, no piso, nas roupas e mobiliários das Unidades participantes. TRIVIÑOS (1992)

Para a inclusão na amostra foram utilizados os seguintes critérios: pacientes conscientes, orientados e em condições de comunicação e funcionários com mínimo de seis meses de atuação na UTI.

Antes da realização da pesquisa o projeto foi encaminhamento ao Comitê de Ética em Pesquisa Médica Humana e Animal do Hospital das Clínicas da Universidade Federal de Goiás. O Termo de Consentimento Livre e Esclarecido foi assinado por todos que participaram da pesquisa, conforme o que recomenda a Resolução 196/96 que trata da pesquisa envolvendo seres humanos.

\section{RESULTADOS E DISCUSSÃO}

Segundo MARZIALE (1990, p. 230), "A cor passa a constituir uma variável de grande importância dentro do ambiente hospitalar, não só pela influência sobre os pacientes, mas também sobre os profissionais que ali atuam".

LACY (2000) refere que as cores do ambiente podem alterar a comunicação, as atitudes e a aparência das pessoas presentes; a cor pode tranqüilizar, diminuir o stress e a violência ou aumentar a vitalidade e a energia. Compreende-se que cada grupo, pacientes ou profissionais, sofre um tipo de influência das cores de acordo com suas necessidades. 


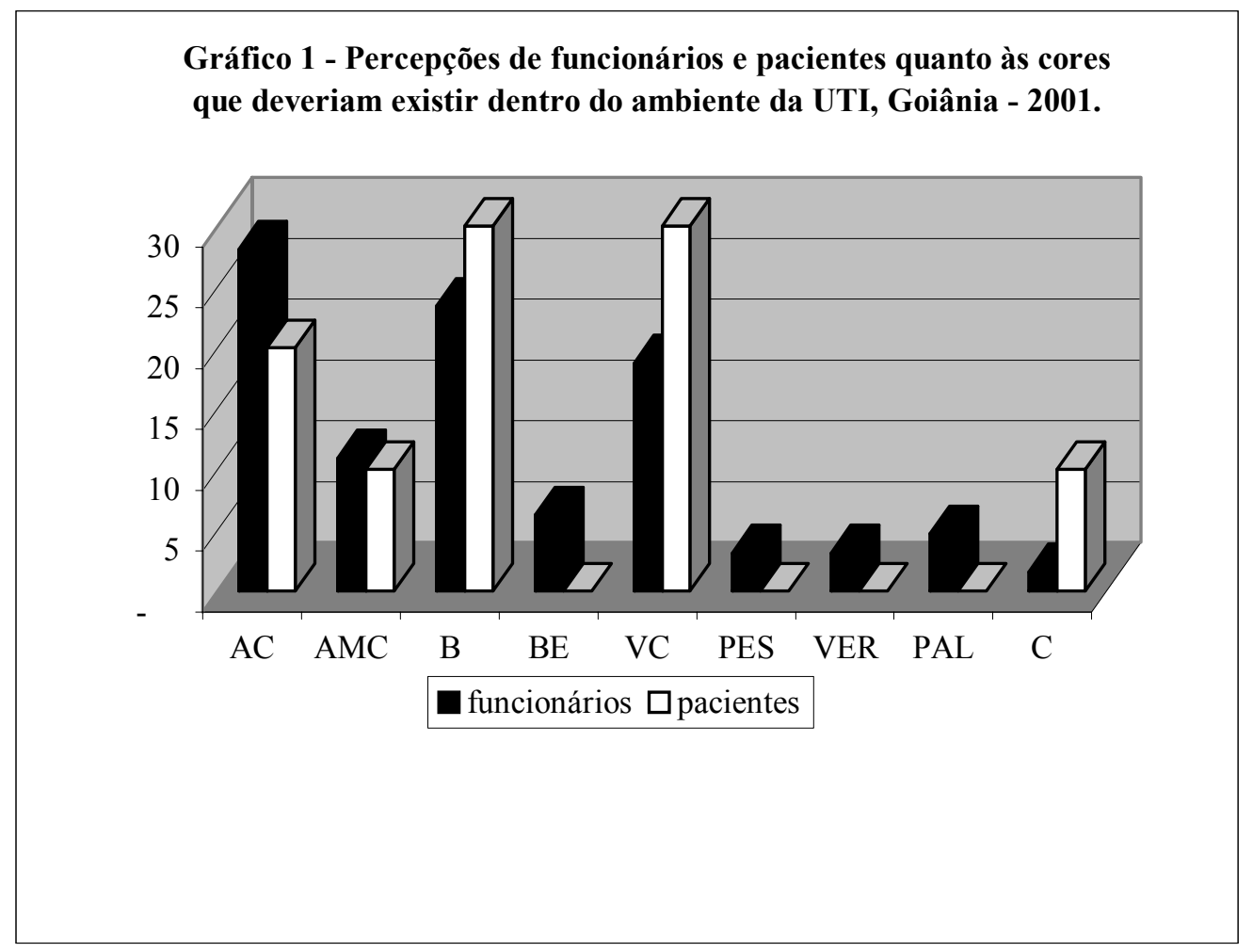

Ao analisar as percepções dos profissionais e pacientes quanto às cores que deveriam existir dentro da UTI, observa-se que as mais citadas pelos profissionais, foram também as sugeridas pelos pacientes: o azul claro $(28 \%)$ para os profissionais e $(20 \%)$ para os pacientes, o branco $(23 \%)$ e $(30 \%)$, o verde claro $(19 \%)$ e $(30 \%)$, e o amarelo claro $(11 \%)$ e $(10 \%)$ respectivamente. Observa-se uma tendência quanto à preferência por estas quatro cores entre os dois seguimentos pesquisados. Chama-se a atenção, o fato de que as cores bege $(6 \%)$, pêssego $(3 \%)$ e palha $(5 \%)$ que são tonalidades que se aproximam do amarelo claro, em percentuais menores, foram citadas pelos profissionais nas U.T.I. Foram mencionadas ainda as cores vermelha $(3 \%)$ pelos profissionais e cinza $(10 \%)$ pelos pacientes.

Estes resultados reforçam os dados encontrados na literatura investigada. VOLLMAR $(199$, p. 65) cita que "para alcançar calma, paz e harmonia no ambiente de moradia e de trabalho, é recomendável usar fundamentalmente tons verdes e azuis. Para trabalho mental criativo, utilizar tons de amarelo..." Em LACY (2000), encontra-se que a cor azul deve ser utilizada especialmente para hospitais e clínicas., pois ela ajuda a reduzir o estresse e a tensão; já o verde é a cor do equilíbrio e da harmonia, ajuda a reduzir a tensão e o estresse. Para FARINA (1990, p. 112), o branco "está associado à simplicidade, limpeza, paz pureza, harmonia, estabilidade". 


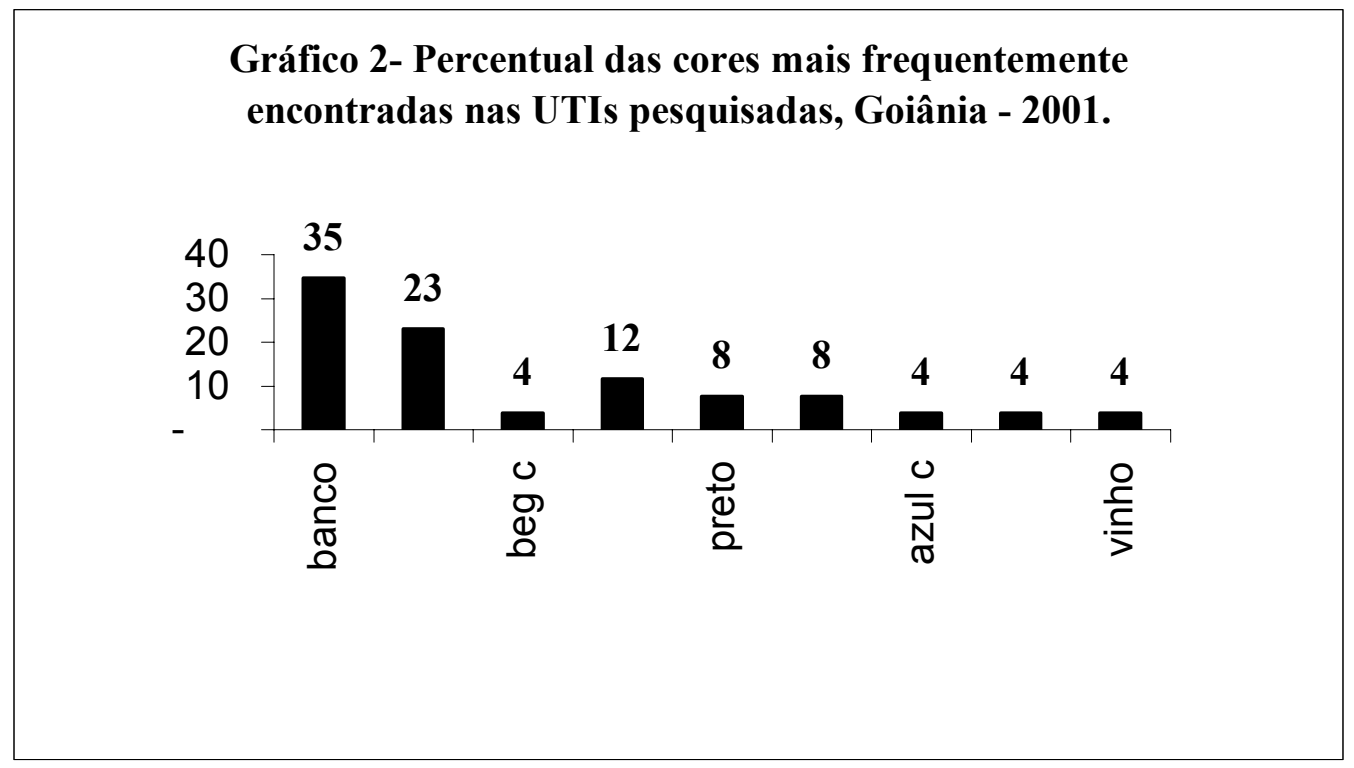

Observa-se utilização maior dentro das UTI pesquisadas das cores brancas $(35 \%)$ e cinza $(23 \%)$, seguidos do bege escuro (12\%), verde claro e preto $(8 \%)$ e pequena utilização do azul claro, verde escuro, vinho e bege claro (4\%).
Há nestes ambientes uma monotonia e neutralidade, em tons que vão do branco ao preto. As outras nuances de cores aparecem num percentual bem menor.

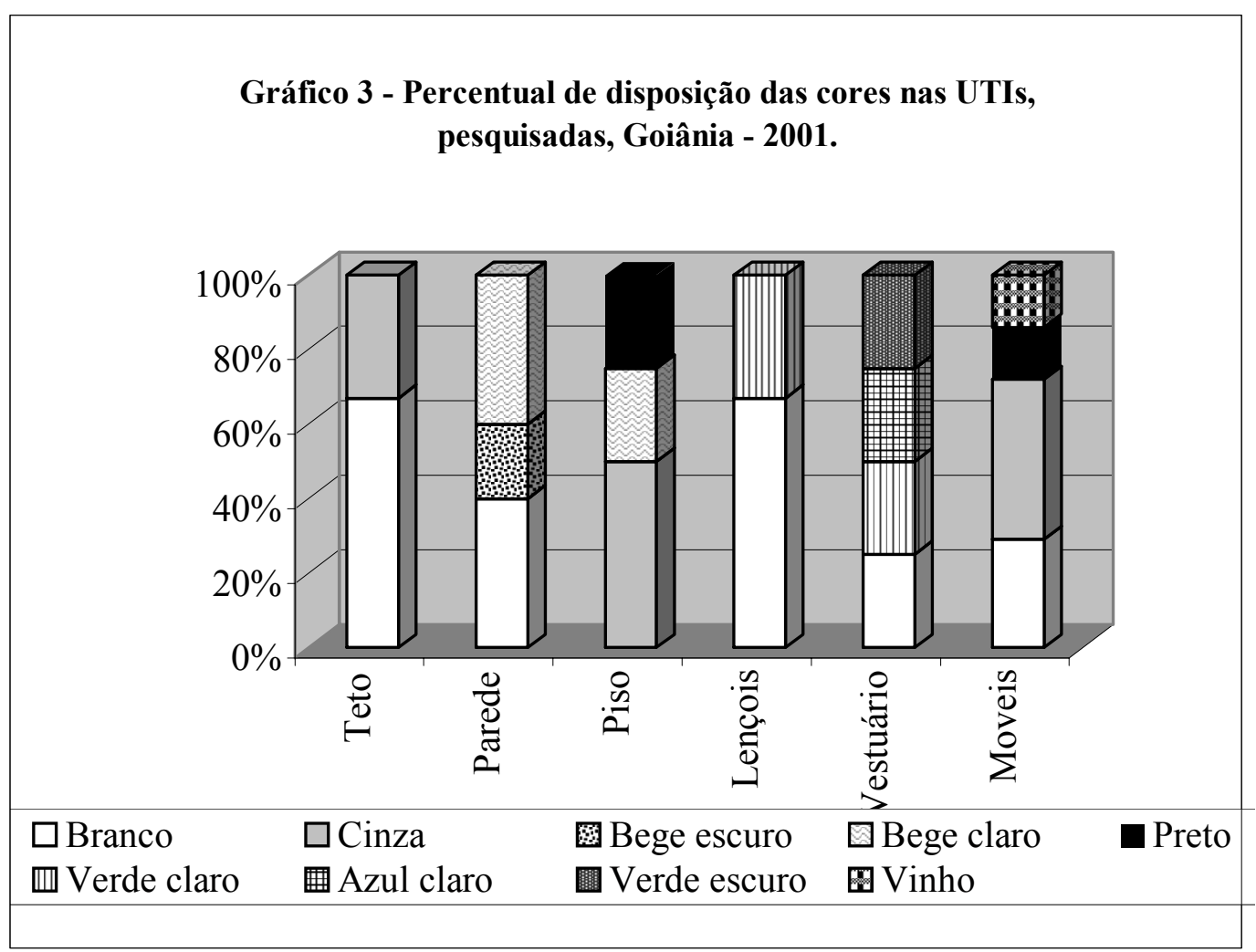

Ao analisar as disposições das cores dentro da UTI, observa-se que no teto, que é o maior campo visual dos pacientes, existe uma predominância das cores branca $(67 \%)$ e cinza $(33 \%)$. As paredes são brancas $(40 \%)$, bege escuro $(20 \%)$ ou bege claro $(40 \%)$. O piso é cinza $(50 \%)$, preto $(25 \%)$ ou bege claro $(25 \%)$. Já as roupas de cama são brancas $(67 \%)$ ou verde claro $(33 \%)$. O vestuário é branco $(25 \%)$, verde claro $(25 \%)$, azul claro $(25 \%)$ ou verde escuro (25\%). O mobiliário é branco (29\%), cinza (43\%), preto $(14 \%)$ e vinho (14\%).

Quanto às associações estabelecidas pelos sujeitos, identificamos as seguintes: 


\section{Ambiente familiar:}

Conforme LACY (2000), os interesses dos cuidadores precisam ser levados em consideração tanto quanto os dos próprios pacientes em tratamento intensivo.

Interessante seria fazer do ambiente hospitalar um local que se assemelhasse com a casa dos pacientes e dos profissionais, como eles mesmos referem:

"Deveria existir cores que dessem a impressão de casa. Paredes mais claras. Quanto mais se aproximar o clima da U.T.I. com o de casa, melhor para o paciente"; E3

"Trazer para U.T.I. a cor de madeira envernizada, cor de minha casa..."; E12

\section{Neutralidade:}

"O branco apesar de neutro é uma cor que não transmite nada", Jatene (1999, p. 20).

"Acho que deveriam ser modificadas as cores.

São muito neutras"; E2

"São quase neutras, podem mudar um pouco"; E11

"Não tenho nada contra a cor da parede porque é neutra, mas poderia ser mais clara..."; E4

\section{Cores claras e leves:}

Cores claras devem ser escolhidas para ambientes sombrios em que a luz do sol não penetra. Se a intenção é alargar um corredor, as cores das paredes também devem ser mais claras. As cores mais escuras farão com que o corredor pareça mais estreito. Cores claras causam uma sensação de leveza e volatilidade, LACY (2000). A grande maioria dos entrevistados concorda que as cores da U.T.I. devem ser claras:

“... deve-se pensar em detalhes de cor, cores mais leves e suaves para os pacientes, as quais são importantes para melhorar 0 ambiente." E4

"Inadequado, não tem um padrão, deveria ser tudo claro"; E20

"Branco nas paredes, piso claro, cores claras." E5

"As cores são claras, o ambiente fica mais claro, mais leve..." E11

"Em geral cores claras, suaves, cores que não pesem o ambiente"; E15

"É importante a cor. Tem que ser cores agradáveis e suaves"; E2

"As cores são boas, são claras": E9

"Acho que tem que ser cores discretas, não usar cores chamativas"; E7

"Cores claras, tranqüiliza e descansa a vista"; E14

"Cores não fortes, mais suaves"; E21

"Gostaria que as paredes fossem brancas.

Clarinho fica fresquinho e asseado. É mais asseado". E18

Cores escuras ou fortes:

"Não gosto das cores nesta U.T.I ., acho triste, fechada e escura"; E12

"Poderia ter cores mais fortes, que chamassem a atenção".E3

"No corredor as cores são mais fortes, o que é bom desperta o funcionário"; E22

\section{Cores alegres e vivas}

"... os quartos dos pacientes poderiam ter cores mais vivas, mais alegres"; E6

"Cores mais alegres, mais colorido"; E8

\section{Tranqüilidade:}

FARINA (1986, p. 107), refere que "o uso do azul no forro, em substituição ao branco, confere ao paciente uma sensação de calma tranqüilidade e bemestar". Observa-se a importância das cores como influência nas sensações de tranqüilidade. De acordo com JATENE (1999), as cores devem ser tranqüilizantes, como os tons pastéis.

“... acho importante porque através das cores você transmite tranqüilidade, alegria, paz,..."; E13

"São cores frias, não permite tranqüilidade, segurança,..."; E16

"No meu entender, o ambiente de recuperação tem que ser um local tranqüilo, que deixe o paciente dormir, tranqüilamente, que seja alegre, claro e que tenha iluminação natural. No hospital você sofre um choque de ambiente, se neste ambiente você se sentir bem, você tem a possibilidade de ajudar o paciente". E3

\section{Cansaço e peso:}

De acordo FARINA (1986), o branco reflete intensamente a luz, ocorrendo o fenômeno de ofuscamento, que ocasiona ao doente uma sensação de cansaço e de peso na cabeça, sendo que este repousa na maioria das vezes de costa e, inevitavelmente, fixando os olhos no teto.
“...Cores claras você olha e não cansa. As cores cansam a gente"; E10
"O creme escuro da parede é uma cor mais forte, se ficar olhando direto cansa". E12
"Branco e azul bem claro, transmite harmonia é menos pesado". E2
"O branco não cansa a gente"; E5

\section{Cores frias e tediosas}

O branco no ambiente de terapia intensiva tem sido uma incógnita, alguns não gostam, entretanto outros já acham o branco como adequado para este ambiente.

"Considero as cores existentes normais, ruins se usassem só o branco"; E1 
"Poderia ter mais cores, tem muito branco, formando um ambiente mais frio e tedioso"; E12

"Cores frias, não transmitem tranqüilidade e segurança. A impressão é que as pessoas são tão frias quanto o ambiente. Usam muito $o$ branco"; E5

\section{Monotonia e monocromatismo}

Existem vários relatos referindo-se ao contraste e à monotonia das cores no ambiente da Unidade de Terapia Intensiva, entendendo como monotonia a utilização de tons claros e escuros de uma mesma cor. O monocromatismo, tornou-se comum, e é possível que seja uma das causas do stress ambiental, LACY (2000). Necessitamos de contraste, que é o uso das cores complementares com seus diferentes tons e matizes. Sendo as cores complementares aquelas que estão em posições contraria uma às outras. Uma das formas de fazer o contraste é usar vários tons de uma cor e depois complementar com sua cor oposta, fazendo desta forma o contraste. O uso de cores contrastantes confere harmonia ao ambiente. Referente a isto, as cores escuras (onde uma boa quantidade de preto foi adicionada à cor) e os tons escuros de cinza não devem ser jamais usados em ambiente para enfermos, LACY (2000).

Tanto os pacientes como os profissionais relataram os danos causados pela monotonia das cores e a importância do contraste e das cores vivas:

\begin{abstract}
"As cores são mortas, branco, cinza ou preto. Melhora com os monitores coloridos". E12

"Cores monótonas, uniformes, cores frias"; E2

"... vira para um lado é tudo de uma cor, olha para outro é tudo da mesma cor. Desta forma, além da monotonia que a doença te impõe, a padronização do ambiente te impõe esta mesma monotonia e isto, acaba cansando o paciente. Independente da cor se utiliza-la sozinha, acaba impondo uma monotonia, devese usar o contraste na U.T.I."; E15

"...deve-se usar cores suaves, com jogo de cores..." E7

“... a cor do Extintor é uma cor forte (amarelo e vermelho), mas em pouca quantidade, faz um contraste e nos tira desta monotonia. Deve-se existir cores que se tornem novidades para $o$ paciente, amarelo canário, sem abusar". E16
\end{abstract}

Para criar ambientes harmoniosos é necessário que se polarizem as cores, de forma semelhante a eletricidade. Todos precisam de cores quentes e frias para dar equilíbrio a qualquer ambiente, LACY (2000).

\section{CONCLUSÃO}

A sensação sombria, monótona e temerosa do ambiente hospitalar é ainda mais acentuada quando da permanência do indivíduo na UTI.
As cores possuem significados para as pessoas e elas estabelecem associações com as cores.

Interessante seria se o ambiente hospitalar fosse um local que se assemelhasse à casa dos pacientes e profissionais. A cor pode auxiliar no estabelecimento do equilíbrio e contribuir para harmonia do corpo, da mente e das emoções. Entre as cores que profissionais e clientes gostariam que existissem dentro da UTI foram encontradas o azul claro, o branco e o verde claro. Entretanto, as que predominam nos ambientes pesquisados são o cinza no piso, o bege claro em paredes, mas o branco é o que predomina no teto, nas paredes e na roupa de cama.

As cores são consideradas coadjuvantes não agressivos do processo terapêutico e, fazendo parte da natureza e, portanto da própria vida, elas devem também estar presentes em todo o processo saúdedoença, inclusive em ambientes como a Unidade de Terapia Intensiva.

\section{REFERÊNCIAS BIBLIOGRÁFICAS}

BRASIL, Ministério da Saúde. Conselho Nacional de Saúde. Resolução no 196/96 sobre pesquisa envolvendo seres humanos. Brasília, 1996.

FARINA, Modesto. Psicodinâmica das cores em comunicação. $4^{a}$ ed. São Paulo: Ed. Edgard Blücher, 1990.

JATENE, Henrique. Arquitetura para Médicos: Planejar um consultório, clínica ou hospital exige especialização. Revista diálogo médico; 14(6): 18-20 setembro 1999.

LACY, Marie Louise. O poder das cores no equilíbrio dos ambientes. 2. ed. São Paulo: Ed. Pensamento, 2000. 144p.

MARZIALE, Maria Helena Palucci, et al. A linguagem das cores no ambiente hospitalar: percepção dos membros da equipe de enfermagem. In: Universidade de São Paulo. Escola de Enfermagem de Ribeirão Preto. Anais do $2^{\circ}$ Simpósio Brasileiro de Comunicação em Enfermagem, 1990. P.228-248.

TOBIAS, Leonice $T$. et al. Humanização na UTI Pediátrica em Florianópolis. Jornal de pediatria. Rio de Janeiro; vol. 60(4): $164-70$, abril 1986.

TRIVIÑOS, Augusto N. S. Introdução à pesquisa em ciências sociais: a pesquisa qualitativa em educação. $1^{\mathrm{a}}$ ed. São Paulo: Ed. Atlas, 1987.

VOLLMAR, Klausbernd. O poder das cores. 2. ed. Porto Alegre: Kuarup, 1997. 75p.

Texto recebido em 04/10/2004

Publicação aprovada em: 10/12/2004 